\title{
Alternating Magnetic Field Prior to Cutting Reduces Wound Responses and Maintains Fruit Quality of Cut cucumis melo L. cv Hetao
}

\author{
Jin Jia, Xiujuan Wang, Junli Lv, Shan Gao and Guoze Wang* \\ School of Mathematics, Physics and Biological Engineering, Inner Mongolia University of Science and Technology, no. \\ 7, Aerding Street, Kundulun District, Baotou, CN-014010 Inner Mongolia, China
}

\begin{abstract}
The quality of fruit targeted for human consumption is affected greatly by the methods used in processing. The objective of this study was to assess a method of treating cantaloupe melons to reduce the wound responses incurred by cutting while maintaining fruit quality. After being treated with an alternating magnetic field (AMF) at the strength of $2 \mathrm{mT}$ for $0,5,10,15,20$, or $25 \mathrm{~min}$, Cucumis melo fruits were cut longitudinally into five pieces and stored at $5^{\circ} \mathrm{C}$ until analysis. The rates of decomposition, electrolyte leakage and respiration, were determined along with fruit firmness, soluble solids and titratable acids. Cutting the melons damaged the quality of fruits, as indicated by lower firmness soluble solids, higher electrolyte leakage, decomposition, respiration and titratable acids in cut slices compared to intact melons. Treatment with AMF before cutting influenced all parameters above, compared to untreated samples, and treatment with $2 \mathrm{mT}$ for $15 \mathrm{~min}$ resulted in reduced respiration rates, lower electrolyte leakage, delayed softening and decomposition, and reduced flows of soluble solids and titratable acid. Therefore, application of AMF treatment prior to cutting is beneficial for reducing wound responses and maintaining quality and flavor of cut Cucumis melo L. cv, which could provide a useful means to increase the market share of this popular fruit crop species.
\end{abstract}

Keywords: Alternating magnetic field (AMF), Freshly cut, Cucumis melo L. cv Hetao, fruit quality.

\section{INTRODUCTION}

The cantaloupe melon (Cucumis melo L. cv Hetao) is a popular and commercially important fruit crop of the Cucurbitaceae family that grows commonly in Inner Mongolia, where it is served freshly cut. Sales trends for longitudinal cuts of the fruit suggest that consumers are willing to pay for the convenience, if quality is perceived to be better than or equal to the quality of uncut melons [1], and if nutritional measures such as the contents of sugars, amino acids, and vitamins are maintained after processing. However, mechanical handling such as cutting, slicing and peeling may cause physical damages during processing, which causes the quality of fruit to deteriorate rapidly [2]. Any such deterioration when melons are cut into individual portions for sale clearly affects the purchasing choices of consumers in stores, and can lead to substantial market losses [3]. Thus, long shelf life has become an important factor in the marketing and modern use of this species. Development of better treatment methods to enable cutting melons during processing could alleviate the damage to fruits, thus enhancing their quality and ultimate food safety. Improving the shelf life of this fruit would also increase its popularity, enabling cantaloupe growers to achieve a larger share of the produce market across China [4].
Cantaloupes are generally valued for their intense aroma and taste, so they have a high commercial value but are highly perishable during their storage life [5]. To broaden the market for them while maintaining the good quality of fruits, several methods have been investigated. For example, the use of an edible coating made of pectin has been tested as a new method to maintain quality while prolonging the shelf life of fresh-cut melon, however that pretreatment masked melon taste and reduced the sensory acceptance scores at the end of the study [6]. Another method that has been tested is the combination of hot water pasteurization of whole cantaloupe with low-dose irradiation of packaged fresh-cut melon to maintain quality [7], but when the temperature was returned to normal, the benefits of staying fresh were no longer maintained [8] so shelf life was not effectively prolonged. Amaro et al. [9] showed that 1methylcyclopropene (1-MCP) can preserve the soluble solids, total phenolics, total carotenoids and carotene contents of fresh-cut cantaloupe, yet some softening occurred, and the treatments were less effective when 1MCP was applied at a low temperature $\left(0^{\circ} \mathrm{C}\right)[10]$.

Thus, there is a need for development of new methods to protect fruits during the cutting process and thus extend their shelf life. Alternating magnetic field (AMF) has potential for this purpose, they are naturally occurring, easy to work with and create no residue or environmental pollution. The use of electromagnetic fields to stimulate the growth and metabolic cascades and control biochemical pathways had been researched, and report had been found that electromagnetic fields have an important role in eliciting the effects of many biological systems [11], and may affect organisms in both 
negative and positive manner such as acceleration of growth and metabolism. Experiments using oscillating magnetic fields have uncovered new effects in the living systems of growth [12]. AMFs are also capable of changing a plant's growth rates [13], so their action on various biological systems can be used as effectively as a means of regulating the biological activity of plants and fruits [14]. For example, in the previous study, magnetic fields of different intensities had varying influences on the biology of PC12 cells [15].

Justo et al. [16] observed that the Escherichia coli had 100 times greater viability when treating with magnetic field for $6.5 \mathrm{~h}$ than the others without treatment. Magnetic field can change the range of molecular organization in living organisms, as to cell membrane, it changed the membrane permeability, the distribution of protein and lipid domains, and the internal molecular distribution of electronic charge inside lipid molecule, all these changes can affect the rate of biochemical reactions, also the magnetic field have some influence on chloroplast, nucleus, proteins, protoplasm and whole cell [17]. Magnetic treatments may also protect plants against adverse environmental conditions such as stress caused by drought [18]; for instance, they are reportedly effective in determining the distribution of apparent microporosity on apple and tomato fruit [19].

As part of the continuous research efforts to identify useful applications of magnetic fields in food processing, the objective of this study was to conduct the first investigation of the effects of AMF on physiological responses and quality of cut cantaloupe. To do so, several parameters were measured, including electrolyte leakage, respiration rate, fruit firmness, content of soluble solids and titratable acid, and rate of decomposition.

\section{MATERIAL AND METHODS}

\subsection{Plant Materials and Treatments}

Cantaloupes were purchased from the city of BaMeng of Inner Mongolia in July. They were carefully selected to have a uniformity of size, color, absence of damage and defects, and with a ripeness of $90 \%$. The instrument used to generate AMF was made in our laboratory. It was comprised of two parallel couples of Helmholtz coil, with the radius of each coil being equal to the distance between them. The two couples were connected in series, and connected to a potential transformer that could transform the direct current power into alternating current power. By adjusting the compensation current of the coils, an AMF was generated with a volume of $40 \times 40 \times 20 \mathrm{~cm}$ (Fig. 1). A table between the two coils provided a surface where fruits were placed for the treatments (Fig. 2).

A total of 240 melons were used, with 40 intact melons undergoing AMF treatment at a strength of $2 \mathrm{mT}$, in each of six time durations: $0,5,10,15,20$, or $25 \mathrm{~min}$. After being treated, they were cut longitudinally into six pieces, and the sliced fruits were used in the following experiment. The cut pieces were placed on a plastic tray and covered with $40 \mu \mathrm{m}-$ thick polyethylene film. All trays, holding six pieces each, were stored at $5^{\circ} \mathrm{C}$ until the fruit had decomposed. During this time, the physical variables were measured daily.

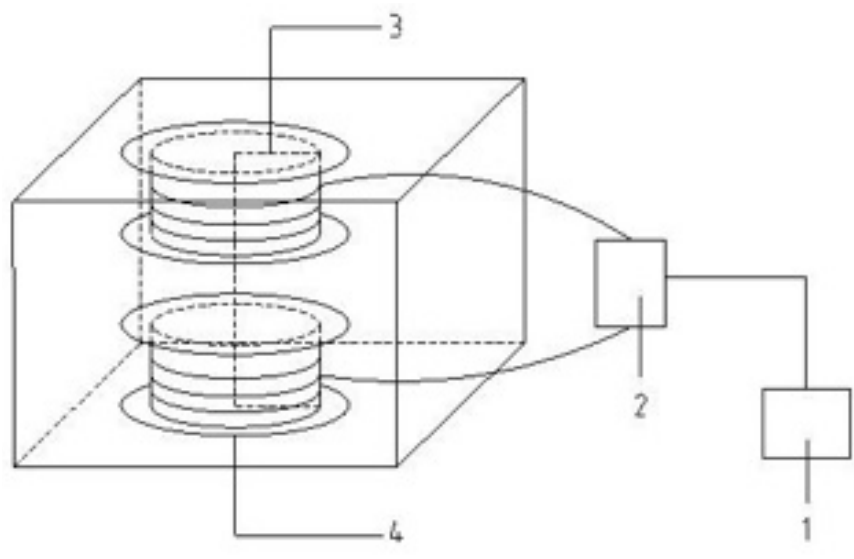

Fig. (1). Schematic drawing of the AMF-generating instrument; 1 is a power source, 2 is a potential transformer, and 3 and 4 are the Helmholtz coils.

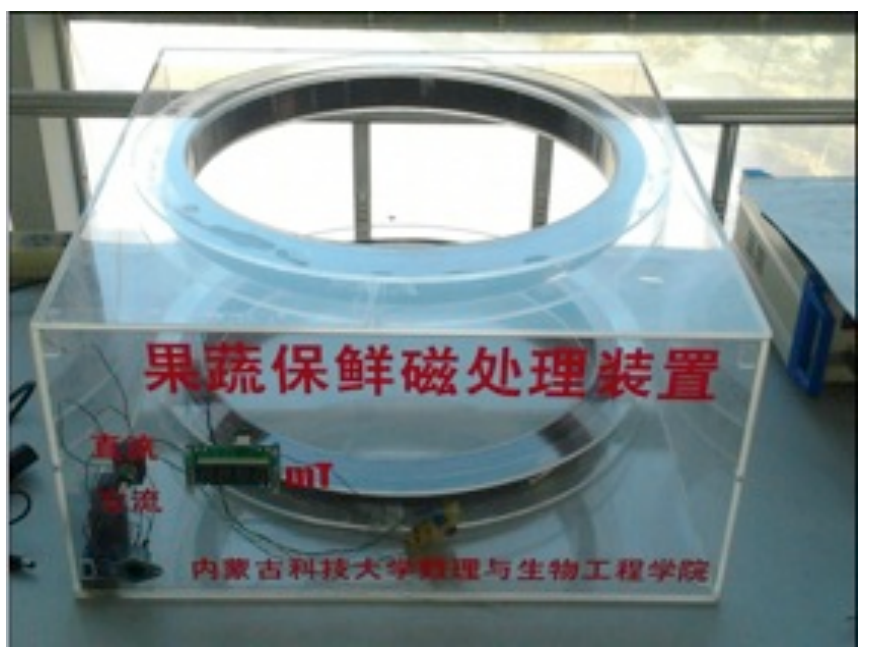

Fig. (2). The finished AMF instrument: 3 intact melons were placed on the table homogeneous for each round of AMF treatment at a strength of $2 \mathrm{mT}$.

\subsection{Fruit Firmness and Soluble Solids}

The firmness of fruit was measured as the force required to puncture the outer cortex using a Texture Analyzer (QTS25 Brookfield, USA) fitted with a of 5-mm diameter probe that had a maximum penetration depth of $10 \mathrm{~mm}$. We set the probe to a target value of $5 \mathrm{~mm}$ penetration into the fruits at a speed of $30 \mathrm{~mm} / \mathrm{min}$. The content of soluble solids was determined using an ATAGO hand-held refractometer.

\subsection{Respiration Rate}

Three pieces of melon slices were placed in $20 \mathrm{~mL}$ of 0.4 $\mathrm{mol} / \mathrm{L} \mathrm{NaOH}$ in a hermetic dryer. The respiration rate of the fruits was calculated according to the method of Alves et al. [20] with a minor modification. The amount of $\mathrm{CO}_{2}$ produced by the melons was calculated by measuring the consumption of $\mathrm{NaOH}$. The respiration rate was expressed as micrograms of $\mathrm{CO}_{2}$ produced per kilogram per hour $\left(\mathrm{mL} \mathrm{kg}^{-}\right.$ $\left.{ }^{1} \mathrm{~h}^{-1}\right)$. 


\subsection{Electrolyte Leakage}

For determining electrolyte leakage, a modification of the method reported by Campos et al. [21] was used. A stainless steel cork borer of $0.5 \mathrm{~cm}$ diameter was used to obtain cylinders of melon tissue. Two 4-mm thick samples were cut from each cylinder. After being rinsed 3 times (2-3 min) with demineralised water, ten pieces were put into $50 \mathrm{ml}$ of demineralised water and shaken at 100 cycles per min for at room temperature. The electrolyte leakage in the solution was measured after $180 \mathrm{~min}$ using a Conductance Bridge (DDS-11A, Yamei Electron Instrument Factory, Shanghai, China). Total conductivity was obtained after keeping the flasks in an oven $\left(90^{\circ} \mathrm{C}\right)$ for $2 \mathrm{~h}$. Results were expressed as percentage of total conductivity.

\subsection{Titratable Acids}

The amount of titratable acids was determined following established methods [22]. In brief, we used a titration of 0.1 $\mathrm{mol} / \mathrm{L} \mathrm{NaOH}$, with phenolphthalein as the indicator of the end point. As $20 \mathrm{~g}$ of fluid was extracted from tissue was transferred into a $250 \mathrm{~mL}$ volumetric flask with a constant volume, then $25 \mathrm{~mL}$ of the solution from the volumetric flask was used as the unit for the statistical analysis of titration results.

\subsection{Rate of Decomposition}

The rate of decomposition of melon slices was measured after being removed from $5^{\circ} \mathrm{C}$ to room temperature at $20^{\circ} \mathrm{C}$ for $24 \mathrm{~h}$ by visual estimation, we counted the number of melon slices that were decomposed, and then divided by the total number of melon slices in the treatment, and expressed this as a rate out of $100 \%$.

\subsection{Statistical Analysis}

All experiments were performed in triplicate. Analysis of variance (ANOVA) between treatment means was carried out with the SPSS 17.0 software using Duncan's one-way test at $\mathrm{P}<0.05$.

\section{RESULTS AND DISCUSSION}

\subsection{Fruit Firmness and Soluble Solids}

The firmness of melon slices that were treated with AMF was higher than the firmness of untreated slices, throughout the entire storage period (Fig. 3). We found that firmness was highest for all fruits within 3 days, then firmness loss was observed by indicating the lower firmness in untreated slices than that in treated fruit. Further, firmness in fruit treated with AMF for 15 min was $54.9 \%$ higher than fruit without AMF treatment on the $4^{\text {th }}$ day. These combined results showed that AMF retarded the softening of fruit tissue. Furthermore, applying AMF for 15 min was the best treatment for maintaining high firmness of melons.

Indeed, firmness is an important parameter that is closely related to fruit maturity, harvest time and quality grade [23]. A decrease in firmness during storage is mainly related to increases in degradative metabolism [24]. Therefore, higher firmness clearly equates to better quality melons. In our experiment, the softening of melons was effectively delayed when samples were treated with AMF.

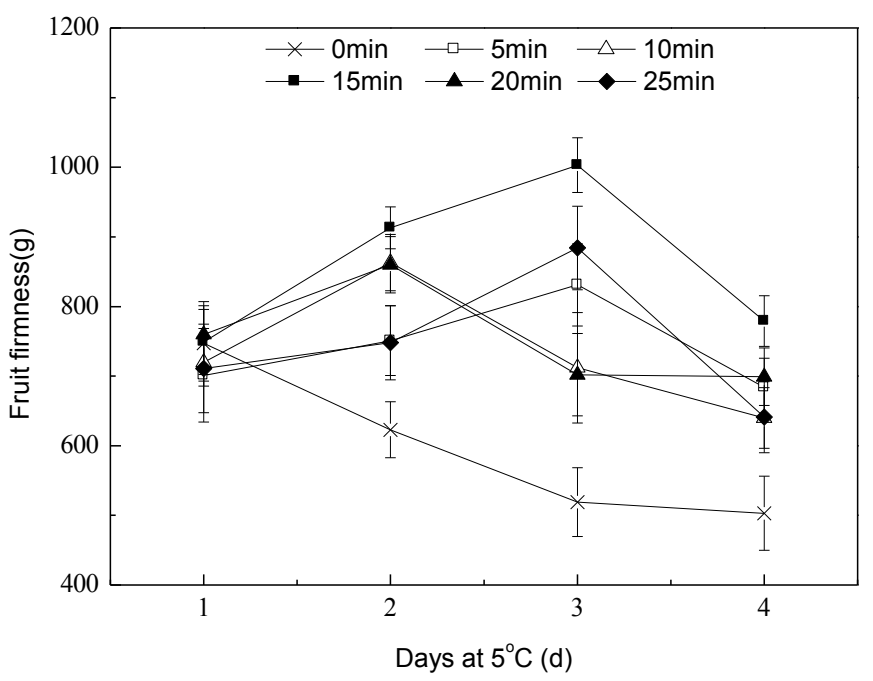

Fig. (3). Changes in the firmness of flesh of cantaloupe slices stored at $5^{\circ} \mathrm{C}$. Before storage, melons were treated with an AMF of $2 \mathrm{mT}$ for $0,5,10,15,20$, or $25 \mathrm{~min}$, and then were cut longitudinally into six pieces.

Soluble solids content, which provides a reflection of the carbohydrate content of fruits, can be divided into soluble and insoluble components, with the soluble component consisting largely of soluble sugars [25]. Sugar content is an important determinant of fruit quality, for example it is a key factor that determines the eating quality of watermelons [26]. We detected a rapid decrease in soluble solids appeared in all samples during the storage period (Fig. 4). Melon slices treated for 20 and 25 min showed little change in soluble solids compared to those without treatment. However, when the treatment time was 5 or $10 \mathrm{~min}$, the soluble solids decreased rapidly. The highest levels of soluble solids were found in cut melon treated with AMF for $15 \mathrm{~min}$ (Fig. 4). Thus, the treatment of $2 \mathrm{mT}$ for $15 \mathrm{~min}$ was able to maintain a high level of soluble solids in melon slices.

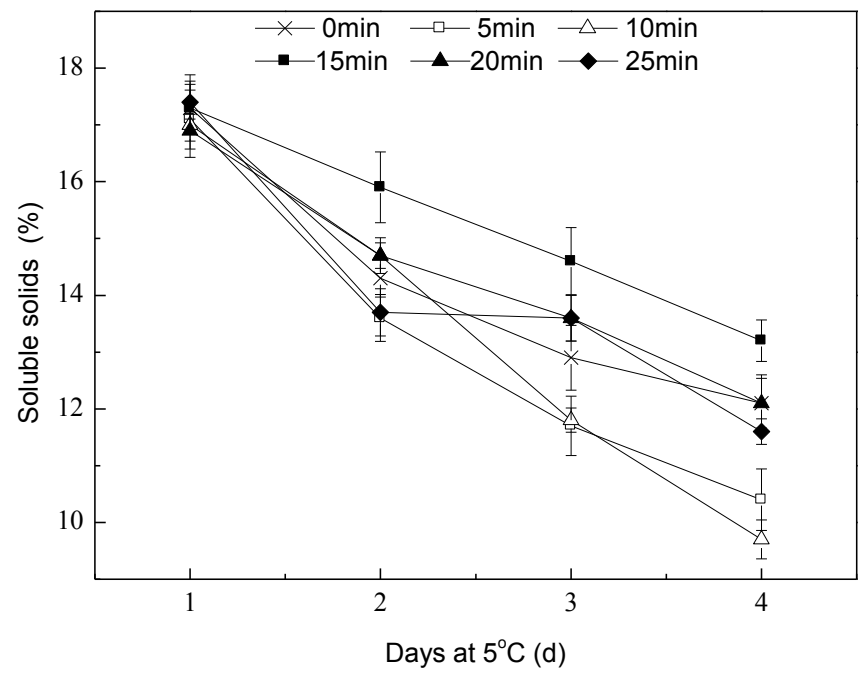

Fig. (4). Changes in the concentration of soluble solids in cantaloupe slices stored at $5^{\circ} \mathrm{C}$. Before storage, melons were treated with an AMF of $2 \mathrm{mT}$ for $0,5,10,15,20$, or $25 \mathrm{~min}$, and then were cut longitudinally into six pieces. 


\subsection{Respiration Rate}

The pretreatment of soybean seeds with magnetic fields is used in agriculture to achieve enhanced crop growth and increased yields [13]. According to Wills et al. [27], the respiration rate of fruits, vegetables and ornamental plants is an excellent indicator of the metabolic activity of tissue, and is therefore an important determinant of a potential product's shelf life.

In our study, treatment times of 5, 10 and $20 \mathrm{~min}$ led to higher respiration rates than those measured in untreated melon slices on the 2 nd day. $\mathrm{CO}_{2}$ production in melon slices increased even when they were treated with AMF, which suggested that the quality of melons deteriorated slowly. However, samples treated for $15 \mathrm{~min}$ had an obviously lower respiration rate than those that were untreated, until the 4th day (Fig. 5). All of these results indicated that wounding caused by cutting increased the rate of respiration, but AMF of $2 \mathrm{mT}$ for $15 \mathrm{~min}$ effectively reduced this wound response.

Some studies have reported that the respiration rate of selected fresh-cut produce is inversely related to shelf life. That is, when the respiration rate of freshly cut products was higher, the shelf life would be shorter, and vice versa [28], such as has been demonstrated with fresh-cut carrots [20]. We have demonstrated that the use of AMF treatment can significantly prolong the shelf life of cantaloupes by slowing respiration.

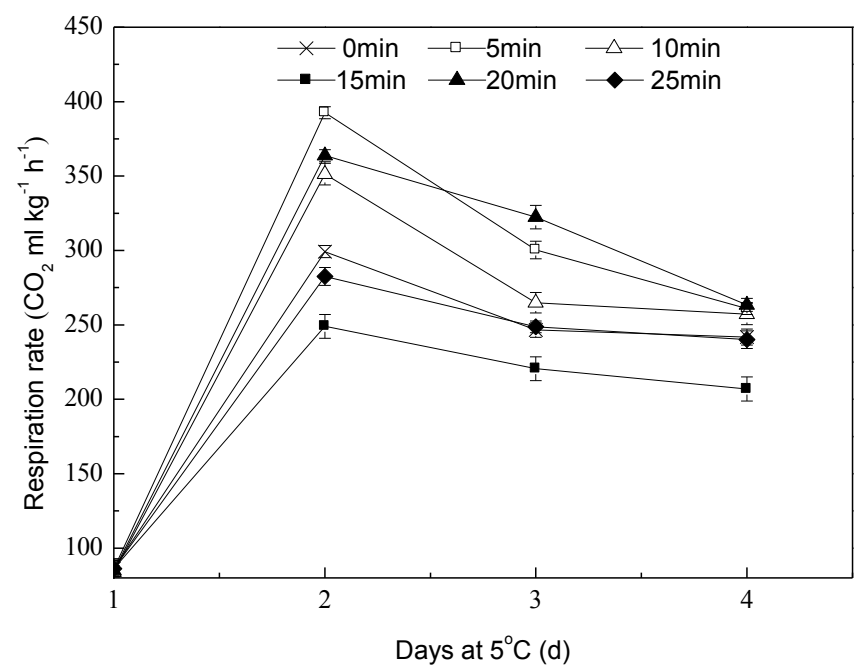

Fig. (5). Changes in the respiration rate of cantaloupe slices stored at $5^{\circ} \mathrm{C}$. Before storage, melons were treated with an AMF of $2 \mathrm{mT}$ for $0,5,10,15,20$, or $25 \mathrm{~min}$, and then were cut longitudinally into six pieces.

\subsection{Electrolyte Leakage}

Sliced fruit, treated with AMF for 0 min and 20 min, had the highest electrolyte leakage during the storage period. However, the lowest electrolyte leakage was observed when the treatment time was $15 \mathrm{~min}$ during the storage period (Fig. 6). In our study, results showed that electrolyte leakage was stimulated by cutting, which supports previous results that electrolyte leakage is a useful parameter to indicate physical damage, because leakage increases to the plasmalemma when wounds to fruit tissue are incurred [29].
Also, Gerasopoulos et al. [30] showed that adverse conditions such as low temperature cause considerable losses of quality during the prolonged shelf life of fruits, apparently related to factors that affect membrane function, and thus, to the more electrolyte leakage. Less electrolyte leakage is consistent with better fruit quality. In this study, AMF of $2 \mathrm{mT}$ for $15 \mathrm{~min}$ was able to effectively reduce electrolyte leakage and maintain good melon quality.

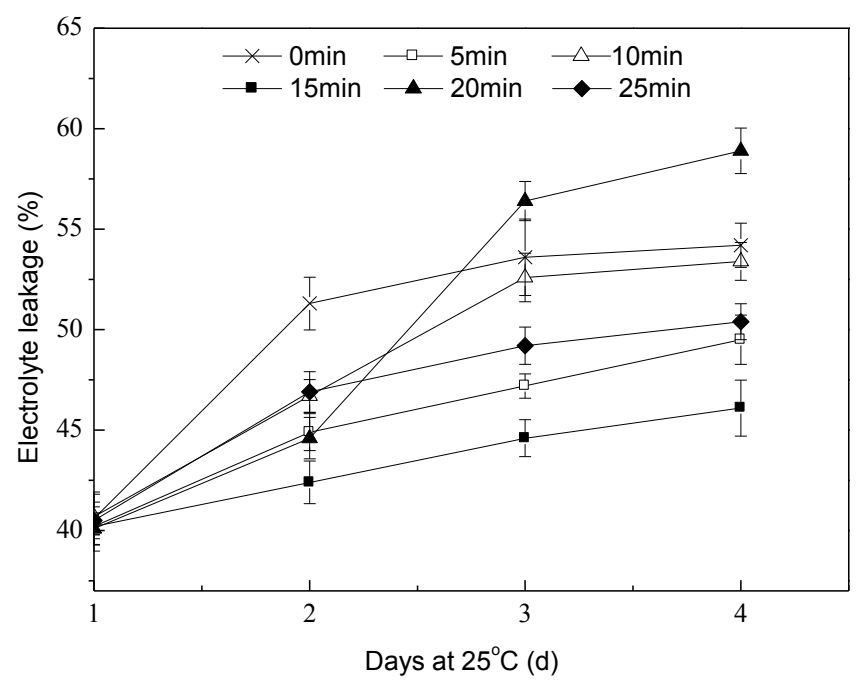

Fig. (6). Changes in the electrolyte leakage from cantaloupe slices stored at $5{ }^{\circ} \mathrm{C}$. Before storage, melons were treated with an AMF of $2 \mathrm{mT}$ for $0,5,10,15,20$, or $25 \mathrm{~min}$, and then were cut longitudinally into six pieces.

\subsection{Titratable Acid}

The amount of titratable acid is another one of the key characters that refelct the taste of fruits [31], lower acidity with little changes in that measure may help to maintain the consistency of fruit flavor. In our report, the cut melons treated with AMF all had lower titratable acid than their untreated counterparts during the first day, even though a rise occured at the cut treat group afterwards. In all of the fruits tested, the amount of titratable acid had a greater range when the treatment time was 10,20 or $25 \mathrm{~min}$. The lowest amount of titratable acid was found when treatment time was $5 \mathrm{~min}$, but it also changed rapidly in that group. However, samples treated for $15 \mathrm{~min}$ not only showed smaller changes, but also had the lowest initial measures of titratable acid (Fig. 7). Similar beneficial results were obtained by Martiñon et al. [4]., who found that the titratable acid changed little in fresh-cut cantaloupe, and was able to delay the postharvest ripening process effectively. These findings indicated that AMF of $2 \mathrm{mT}$ for $15 \mathrm{~min}$ can maintain the desired taste of melons.

\subsection{Rate of Decomposition}

Tripathi et al. [32] reported that fruits with higher moisture content and nutrient composition were highly susceptible to attack by pathogenic fungi, which might make them unsuitable for eating. Clearly, fruit quality is better when the rate of decay is lower. The use of AMF might be able to address this problem by changing enzyme activity, 


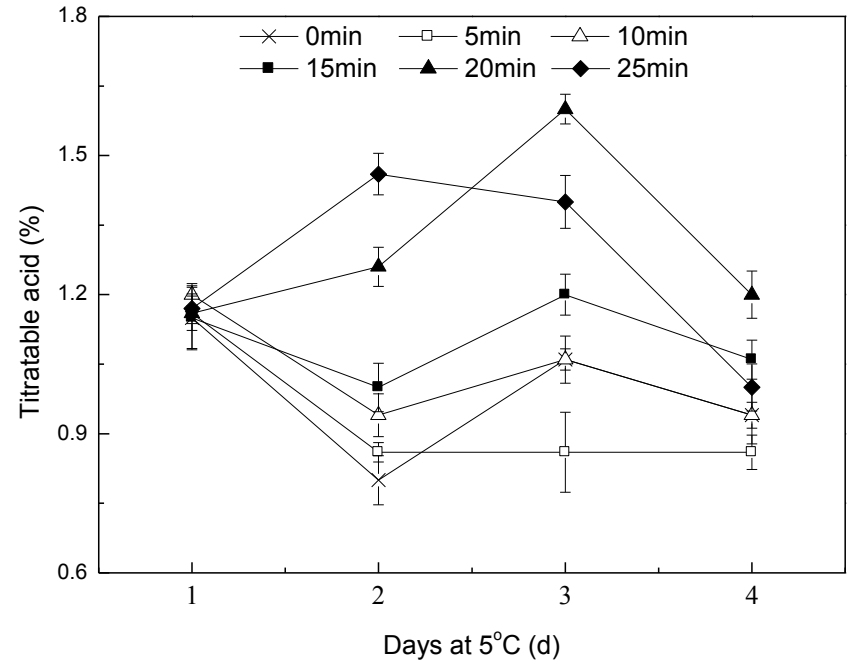

Fig. (7). Changes in the titratable acid in cantaloupe slices stored at $5^{\circ} \mathrm{C}$. Before storage, melons were treated with an AMF of $2 \mathrm{mT}$ for $0,5,10,15,20$, or $25 \mathrm{~min}$, and then were cut longitudinally into six pieces.

gene expression, and the release of calcium from intracellular storage sites [33]. In our experiment, the rate of decomposition in untreated, cut melons increased faster than the rate in treated, cut melons, within 4 days (Fig. 8). Samples treated with AMF for 5 and $10 \mathrm{~min}$ had a lower decomposition rate, but not significantly so $(\mathrm{P}>0.05)$. A possible reason may be that the periods of AMF treatment were not long enough. When treatment lasted for $15 \mathrm{~min}$, the rate of decomposition was obviously lower. Prolonging the treatment time further, to 20 or $25 \mathrm{~min}$, did not lower the decomposition rate further (Fig. 8). These results showed that an optimum length of AMF treatments for cantaloupe would be $15 \mathrm{~min}$, to achieve a much lower decomposition rate.

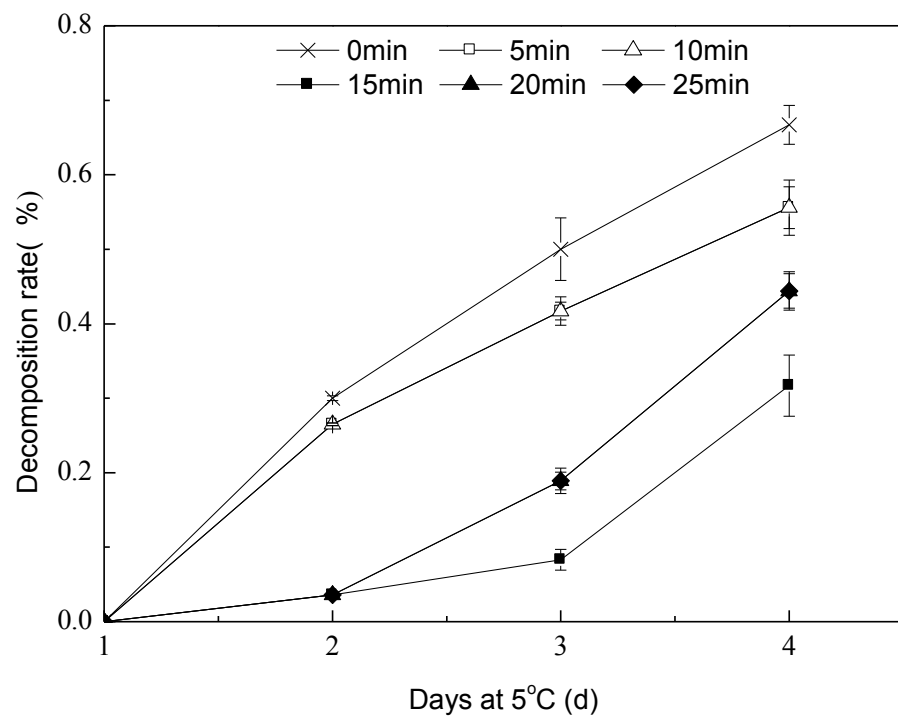

Fig. (8). Changes in the rate of decomposition of cantaloupe slices stored at $5^{\circ} \mathrm{C}$. Before storage, melons were treated with an AMF of $2 \mathrm{mT}$ for $0,5,10,15,20$, or $25 \mathrm{~min}$, and then were cut longitudinally into six pieces.

\section{CONCLUSION}

In conclusion, we demonstrated that $\mathrm{AMF}$ treatment for 15 min was able to reduce the respiration rate and electrolyte leakage, delay softening and decomposition rates, and also reduce the flow of soluble solids and titratable acids in cut cantaloupes. Reductions in all of these parameters are related to good quality in cantaloupe fruits. Therefore, the application of AMF at $2 \mathrm{mT}$ for $15 \mathrm{~min}$ before cutting is the best treatment to reduce wound responses and maintain the quality and good flavor of fruits in this important crop species.

\section{CONFLICT OF INTEREST}

Authors declared that there is no conflict of interest.

\section{ACKNOWLEDGEMENTS}

This research was supported by the National Natural Science Foundation of China (NNSFC-31260406) and Inner Mongolia university of science and technology Innovation Foundation for Young Core Instructor (2014QNGG06).

\section{REFERENCES}

[1] Beaulieu J, Lea JM. Quality changes in cantaloupe during growth, maturation, and in stored fresh-cut cubes prepared from fruit harvested at various maturities. J Am Soc Hortic Sci 2007; 132(5): 720-8.

[2] Watada AE, Ko NP, Minott DA. Factors affecting quality of freshcut horticultural products. Postharvest Biol Tec 1996; 9: 115-25.

[3] Manohar SH, Murthy HN. Estimation of phenotypic divergence in a collection of Cucumis melo including shelf-life of fruit. Sci Hortic-Amsterdam 2012; 148: 74-82.

[4] Martiñon ME, Moreira RG, Castell-Perez ME, Gomes C. Development of a multilayered antimicrobial edible coating for shelflife extension of fresh-cut cantaloupe (Cucumis melo L.) stored at $4^{\circ} \mathrm{C}$. LWT - Food Sci Tec 2014; 56: 341-50.

[5] Huang CH, Zong L, Buonanno M, Xue X, Wang T, Tedeschi A. Impact of saline water irrigation on yield and quality of melon (Cucumis melo cv. Huanghemi) in northwest China. Eur J Agr 2012; 43: 68-76.

[6] Cristhiane C, Ferrari-Claire IGL, Sarantópoulos SM, CarmelloGuerreiro MDH. Effect of osmotic dehydration and pectin edible coatingson quality and shelf life of fresh-cut melon. Food Bio Tec 2013; 6: 80-91.

[7] Fan XT, Annous BA, Sokorai KJB, Burke A, Mattheis JP. Combination of hot-water surface pasteurization of whole fruit and low-dose gamma irradiation of fresh-cut cantaloupe. $\mathrm{J}$ food protect 2006; 69(4): 912-9.

[8] Chan HT, Tam S, Seo ST. Papaya polygalacturonase and its role in thermally injured ripening fruit. J Food Sci 1981; 46: 190-7.

[9] Amaro AL, Fundo JF, Oliveira A, Beaulieu JC, Fernandez-Trujillo JP, Almeida DPF. 1-Methylcyclopropene effects on temporal changes of aroma volatiles and phytochemicals of fresh-cut cantaloupe. J Sci food Agr 2013; 93(4): 828-37.

[10] Villalobos-Acuña MG, Biasi WV, Mitcham EJ, Holcroft D. Fruit temperature and ethylene modulate 1-MCP response in 'Bartlett' pears. Postharvest Biol Tec 2011; 60(1): 17-23.

[11] Pilla AA, Markov MS. Bioeffects of weak electromagnetic fields. Rev environ health 1994; 10: 155-69.

[12] Moore RL. Biological effects of magneticfields: studies with microorganisms. Can J Microbiol 1979; 25: 1145-51.

[13] Radhakrishnan R, Kumari BDR. Pulsed magnetic field: A contemporary approach offers to enhance plant growth and yield of soybean. Plant Physiol Bioch 2012; 51: 139-44.

[14] Cakmak T, Cakmak ZE, Dumlupinar R, Tekinay T. Analysis of apoplastic and symplastic antioxidant system in shallot leaves: Impacts of weak static electric and magnetic field. J Plant Physiol 2012; 169(11): 1066-73. 
[15] Zhang Y, Ding J, Duan W. A study of the effects of flux density and frequency of pulsed electromagnetic field on neurite outgrowth in PC12 cells. J Biol Phys 2006, 32(1): 1-9.

[16] Justo OR, Pérez VH, Alvarez DC, Alegre RM. Growth of Escherichia coliunder extremely low-frequency electromagnetic fields. Appl Biochem Biotech 2006; 134: 155-63.

[17] Hunt RW, Zavalin A, Bhatnagar A, Chinnasamy S, Das KC. Electromagnetic Biostimulation of Living Cultures for Biotechnology, Biofuel and Bioenergy Applications. Int J Mol Sci 2009; 10(10): 4515-58.

[18] Selim AH, El-Nady MF. Physio-anatomical responses of drought stressed tomato plants to magnetic field. Acta Astronaut 2011; 69: 387-96.

[19] Musse M, Guio FD, Quellec S, Cambert M, Challois S, Davenel A. Quantification of microporosity in fruit by MRI at various magnetic fields: comparison with X-ray microtomography. Magn Reson Imaging 2010; 28(10): 1525-34.

[20] Alves JA, Júnior RAB, Boas EVdBV. Identification of respiration rate and water activity change in fresh-cut carrots using biospeckle laser and frequency approach. Postharvest Biol Tec 2013; 86: 3816.

[21] Campos PS, Quartin V, Ramalho JC, Nunes MA. Electrolyte leakage and lipid degradation account for cold sensitivity in leaves of Coffea sp.plant. J Plant Physiol 2003; 160: 283-92.

[22] Xie LJ, Ye XQ, Liu DH, Ying Y. Prediction of titratable acidity, malic acid and citric acid in bayberry fruit by near-infrared spectroscopy. Food Res Int 2011; 44: 2198-204.

[23] Peng YK, Lu RF. Prediction of apple fruit firmness and soluble solids content using characteristics of multispectral scattering images. J Food Eng 2007; 82(2): 142-52.

[24] Mao LC, Wang GZ, Que F. Application of 1-methylcyclopropene prior to cutting reduces wound responses and maintains quality in cut kiwifruit. J Food Eng 2007; 78: 361-5.
[25] Burdon J, Lallu N, Pidakala P, Barnett A. Soluble solids accumulation and postharvest performance of 'Hayward' kiwifruit. Postharvest Biol Technol 2013; 80: 1-8.

[26] Jie DF, Xie LJ, Rao XQ, Ying YB. Using visible and near infrared diffuse transmittance technique to predict soluble solids content of watermelon in an on-line detection system. Postharvest Biol 2014; 90: $1-6$

[27] Wills R, McGlasson B, Graham D, Joyce D. Postharvest. An introduction tothe physiology and handling of fruit, vegetables and ornamentals. $4^{\text {th }}$ ed. Adelaide, Australia, 1998; p. 262.

[28] Waghmare RB, Mahajan PV, Annapure US. Modelling the effect of time and temperature on respiration rate of selected fresh-cut produce. Postharvest Biol Tec 2013; 80: 25-30.

[29] Antunes MDC, Sfakiotakis EM. Changes in fatty acid composition and electrolyte leakage of 'Hayward' kiwifruit during storage at different temperatures. Food Chem 2008; 110: 891-6.

[30] Gerasopoulos D, Chlioumis G, Sfakiotakis E. Non-freezing points below zero induce low-temperature breakdown of kiwifruit at harvest. J Sci Food Agric 2006; 86(6): 886-90.

[31] Vallone S, Sivertsen H, Anthon GE, Barrett DM, Mitcham EJ, Ebeler SE, Zakharov F. An integrated approach for flavour quality evaluation in muskmelon (Cucumis meloL. reticulatus group) during ripening. Food Chem 2013; 139: 171-83.

[32] Tripathi P, Dubey NK. Exploitation of natural products as an alternative strategy to control postharvest fungal rotting of fruit and vegetables. Postharvest Biol Technol 2004; 32: 235-45.

[33] Uckun FM. Exposure of B-lineage lymphoid cells to low energy electromagnetic fields stimulates Lyn kinase. J Biochem Chem 1995; 270: 27666-670

(C) Jia et al.; Licensee Bentham Open.

This is an open access article licensed under the terms of the Creative Commons Attribution Non-Commercial License (http://creativecommons.org/licenses/ by-nc/3.0/) which permits unrestricted, non-commercial use, distribution and reproduction in any medium, provided the work is properly cited. 